\title{
Renal Fanconi syndrome with meropenem-containing regimen in drug- resistant tuberculosis
}

\begin{abstract}
From the authors:
We read with great interest the correspondence by ABADIE et al. [1] describing the case of extensively drug-resistant tuberculosis patient developing renal Fanconi syndrome while receiving a meropenem/ amoxicillin-clavulanate-containing regimen.

The International Carbapenem Study Group centres collected data on 96 patients treated with meropenem-clavulanate and 84 patients with imipenem-clavulanate. Carbapenem and $\beta$-lactam/lactamase inhibitor combinations were well tolerated; no cases of Fanconi syndrome were encountered [2, 3]. Other groups have also published their experience and there were no cases of Fanconi syndrome (table 1) [11].

Meropenem dosing and duration were heterogeneous in our study group; the majority of patients were administered meropenem for a median of 85 days (range 49-156 days), particularly during the intensive phase or until their sputum culture conversion [2]. Only the Belgian team prescribed a higher dosage of meropenem for more extended periods [10] (table 1 [2-10]). Meropenem/amoxicillin-clavulanate, given its bactericidal qualities, appears ideally placed in the intensive phase until sputum culture conversion occurs.

If required, ertapenem-clavulanate may be used in the continuation phase [8].

Several drugs are known to cause proximal renal tubular acidosis (RTA) with Fanconi syndrome. It can be caused by several drugs including aminoglycosides, rifampicin, cisplatin and tenofovir dipivoxil fumarate. Generally, RTA is reversible by removing the offending drug. Meropenem and amoxicillin-clavulanate are
\end{abstract}

TABLE 1 Studies available in the literature reporting on carbapenems for the treatment of drug-resistant tuberculosis

\begin{tabular}{|c|c|c|c|c|}
\hline First author [ref.] & $\begin{array}{l}\text { XDR-TB cases out of the total } \\
\text { number of cases studied }\end{array}$ & Control group & Adverse reactions & Carbapenem and dosage \\
\hline Chambers [4] & $2 / 10(20.0 \%)$ & No & Not done & Imipenem $1 \mathrm{~g}$ twice daily \\
\hline De LoRenzo [6] & $9 / 37(24.3 \%)$ & Yes & $5 / 37(13.5 \%)$ & Meropenem $1 \mathrm{~g}$ three times daily \\
\hline VAN RIJN [7] & ND & No & $2 / 18(11.1 \%)$ & Ertapenem $1 \mathrm{~g}$ once daily \\
\hline TIBERI [8] & $2 / 5(40.0 \%)$ & No & $0 / 5(0.0 \%)$ & Ertapenem $1 \mathrm{~g}$ once daily \\
\hline TIBERI [9] & $57 / 84(67.9 \%)$ & Yes & $3 / 56(5.4 \%)$ & Imipenem $500 \mathrm{mg}$ four times daily \\
\hline TIBERI [3] & Imipenem 57/84 (67.9\%) & No & Imipenem 3/56 (5.4\%) & Imipenem 500 mg four times daily \\
\hline Payen [10] & $\begin{array}{c}\text { Meropenem } 4 / / 96(49.0 \%) \\
15 / 18(83.3 \%)^{\pi}\end{array}$ & No & $\begin{array}{c}\text { Meropenem } 6 / 43(6.5 \%) \\
0 / 18(0.0 \%)\end{array}$ & $\begin{array}{l}\text { Meropenem } 2 \mathrm{~g} \text { three times daily then } \\
2 \mathrm{~g} \text { twice daily }\end{array}$ \\
\hline
\end{tabular}

XDR-TB: extensively drug-resistant tuberculosis; ND: not declared. \#: International Carbapenem Study Group cohorts; ๆ: children were included in this study.

@ERSpublications

Renal Fanconi syndrome reported as rare adverse event during treatment of XDR-TB with meropenem http://ow.ly/3RHG30hVsef

Cite this article as: Tiberi S, Payen M-C, Sotgiu G, et al. Renal Fanconi syndrome with meropenemcontaining regimen in drug-resistant tuberculosis. Eur Respir J 2018; 51: 1702187 [https://doi.org/10.1183/ 13993003.02187-2017]. 
not typically given for prolonged periods or in combination. In normal circumstances, Fanconi syndrome has not been regularly reported for either of the two drugs and could be considered rare.

The occurrence of this rare adverse event, related to a drug with well documented toxicity, and the paucity of published evidence on their safety and tolerability advocates for active drug safety monitoring of anti-TB medications [12-14]. Data collection is essential for clinicians and drug advisory bodies to ensure patient safety. Further attention with regards to formulations and preparation of meropenem, as well as its subsequent storage temperature, is also worth considering.

Simon Tiberi ${ }^{1,2,8}$, Marie-Christine Payen ${ }^{3,8}$, Giovanni Sotgiu $\oplus^{4}$, Lia D’Ambrosio ${ }^{5,6}$, Rosella Centis ${ }^{5}$, Jan-Willem Alffenaar ${ }^{7}$ and Giovanni Battista Migliori $\oplus^{5}$

${ }^{1}$ Blizard Institute, Barts and The London School of Medicine and Dentistry, Queen Mary University, London, UK. ${ }^{2}$ Division of Infection, Royal London Hospital, Barts Health NHS Trust, London, UK. ${ }^{3}$ Division of Infectious Diseases, CHU Saint-Pierre, Université Libre de Bruxelles (ULB), Brussels, Belgium. ${ }^{4}$ Clinical Epidemiology and Medical Statistics Unit, Dept of Clinical and Experimental Medicine, University of Sassari, Sassari, Italy. ${ }^{5}$ World Health Organization Collaborating Centre for Tuberculosis and Lung Diseases, Maugeri Care and Research Institute, Tradate, Italy. ${ }^{6}$ Public Health Consulting Group, Lugano, Switzerland. ${ }^{7}$ University of Groningen, University Medical Center Groningen, Dept of Clinical Pharmacy and Pharmacology, Groningen, The Netherlands. ${ }^{8}$ These authors contributed equally.

Correspondence: Giovanni Battista Migliori, WHO Collaborating Centre for TB and Lung Diseases, Fondazione S. Maugeri, Care and Research Institute, via Roncaccio 16, 21049 Tradate, Italy.

E-mail: giovannibattista.migliori@icsmaugeri.it

Received: Oct 242017 | Accepted after revision: Dec 272017

Conflict of interest: None declared.

\section{References}

1 Abadie ME, Strich JR, Kim T, et al. Renal Fanconi syndrome with meropenem/amoxicillin-clavulanate during treatment of extensively drug-resistant tuberculosis. Eur Respir J 2017; 50: 1702023.

2 Tiberi S, Payen MC, Sotgiu G, et al. Effectiveness and safety of meropenem/clavulanate-containing regimens in the treatment of MDR- and XDR-TB. Eur Respir J 2016; 47: 1235-1243.

3 Tiberi S, Sotgiu G, D’Ambrosio L, et al. Comparison of effectiveness and safety of imipenem/clavulanate- versus meropenem/clavulanate-containing regimens in the treatment of MDR- and XDR-TB. Eur Respir J 2016; 47: $1758-1766$.

4 Chambers HF, et al. Imipenem for treatment of tuberculosis in mice and humans. Antimicrob Agents Chemother 2005; 49: 2816-2282.

5 Palmero D, et al. First series of patients with XDR and pre-XDR-TB treated with regimens that included meropenen-clavulanate in Argentina. Arch Bronconeumol 2015; 51: e49-52n.

6 De Lorenzo S, et al. Efficacy and safety of meropenem-clavulanate added to linezolid-containing regimens in the treatment of MDR-/XDR-TB. Eur Respir J 2013; 41: 1386-1392.

7 Van Rijn SP, et al. Pharmacokinetics evaluation of ertapenem in patients with treatment of multidrug-resistant tuberculosis. Eur Respir J 2016; 47: 1229-1234.

8 Tiberi S, D'Ambrosio L, De Lorenzo S, et al. Ertapenem in the treatment of multidrug-resistant tuberculosis: first clinical experience. Eur Respir J 2016; 47: 333-336. doi:10.1183/13993003.01278-2015.

9 Tiberi S, et al. Effectiveness and safety of imipenem-clavulanate added to an optimized background regimen (OBR) versus OBR control regimens in the treatment of multidrug-resistant and extensively drug-resistant tuberculosis. Clin Infect Dis 2016; 62: 1188-1190.

10 Payen MC, Muylle I, Vandenberg O, et al. Meropenem-clavulanate for drug-resistant tuberculosis: a follow-up of relapse free cases. Int $J$ Tuberc Lung Dis 2018; 22: 34-39.

11 Sotgiu G, D'Ambrosio L, Centis R, et al. Carbapenems to treat multidrug and extensively drug-resistant tuberculosis: a systematic review. Int J Mol Sci 2016; 17: 373

12 Falzon D, Schunemann HJ, Harausz E, et al. World Health Organization treatment guidelines for drug-resistant tuberculosis, 2016 update. Eur Respir J. 2017; 49: 1602308.

13 Fox GJ, Benedetti A, Cox H, et al. Group 5 drugs for multidrug-resistant tuberculosis: individual patient data meta-analysis. Eur Respir J 2017; 49: 1600993.

14 Caminero JA, Piubello A, Scardigli A, et al. Proposal for a standardized treatment regimen to manage pre- and extensively drug-resistant tuberculosis cases. Eur Respir J 2017; 50: 1700648. 